\title{
RELAÇÕES ENTRE ATRIBUTOS DO SOLO E VEGETAÇÕES DA REGIÃO ECOTONAL DO MÉDIO RIO SÃO FRANCISCO, BRASIL
}

\author{
Daniel Meira Arruda(1), Carlos Ernesto Gonçalves Reynaud Schaefer ${ }^{(2)^{*}}$ e \\ Mateus Lanna Borges de Moraes ${ }^{(3)}$
}

(1) Universidade Federal de Viçosa, Departamento de Biologia Vegetal, Programa de Pós-graduação em Biologia Vegetal, Viçosa, Minas Gerais, Brasil.

(2) Universidade Federal de Viçosa, Departamento de Solos, Viçosa, Minas Gerais, Brasil.

(3) Universidade Federal de Viçosa, Departamento de Solos, Programa de Pós-graduação em Solos e Nutrição de Plantas, Viçosa, Minas Gerais, Brasil.

* Autor correspondente.

E-mail: carlos.schaefer@ufv.br

\section{RESUMO}

A região do Médio São Francisco representa um amplo espaço territorial, com marcante sazonalidade climática, diversidade de rochas, paisagens, solos, e, consequentemente, formações vegetais. No entanto, as relações entre as características edáficas e suas formações vegetais são pouco esclarecidas. Este estudo apresenta uma relação dos atributos edáficos, determinante para o estabelecimento de savana-estépica, savana-estépica florestada, savana, floresta estacional semidecidual e floresta estacional decidual nessa região, com base na análise de 166 perfis de solos. Em geral, os solos sob savana foram mais lixiviados e arenosos, álicos e restrito aos topos das paisagens; e os sob savana-estépica foram eutróficos, porém sódicos ou solódicos, e rasos, sempre associados às partes mais baixa da paisagem. A floresta estacional semidecidual apresentou forte variação dos atributos edáficos, indicando que sua ocorrência se baseia, principalmente, na disponibilidade de água. Houve grande semelhança entre os solos de savana-estépica florestada e floresta estacional decidual, sendo todos geralmente eutróficos, alcalinos e bem desenvolvidos, e suas diferenças restritas ao aspecto fisionômico da vegetação. Os domínios fitogeográficos do semiárido apresentaram-se pedologicamente bem diferenciados, sendo as savanas (cerrados) e savana-estépica (caatingas) similares às suas respectivas áreas nucleares. Além disso, as florestas estacionais deciduais evidenciaram atributos edáficos bem contrastantes com os domínios vizinhos, destacando essas formações como uma entidade fitogeográfica distinta.

Palavras-chave: fitogeografia, geobotânica, relação solo-vegetação, semiárido brasileiro. 


\title{
ABSTRACT: RELATIONSHIP BETWEEN SOIL PROPERTIES AND VEGETATION IN THE ECOTONE REGION OF THE MIDDLE SÃO FRANCISCO RIVER VALLEY, BRAZIL
}

\begin{abstract}
The Middle São Francisco River valley is a vast territorial area with marked seasonal change and diversity of lithology, landscapes, soil, and vegetation. However, the relationships between soil characteristics and plant communities are poorly known. In this study, we show the relationships between key soil properties that determine the establishment of savanna-steppe, wooded savanna-steppe, savanna, semideciduous forest, and deciduous forest in this region through analysis of 166 soil profiles. In general, savanna soils are much more leached, Al-saturated, and sandier, and they are located in the highlands of the regional landscape. Savanna-steppe soils are eutrophic, yet sodic or solodic and shallow, always associated with lowlands. The semideciduous forests are highly variable in terms of soil properties, and their distribution seems to be controlled by water availability. There is great similarity between wooded savanna-steppe soils and deciduous forest soils, which are overall eutrophic, alkaline, and well developed, so that phytophisiognomy is the main difference between these two formations. The semiarid phytogeography of this ecotonal zone is highly influenced by soil properties, with great soil contrasts between savanna (Cerrado) and savanna-steppe (Caatinga), which are very similar to their respective core reference areas. In comparison to the neighboring Caatinga and Cerrado, the deciduous forests have highly contrasting soil properties, highlighting them as a separate phytogeographic entity.
\end{abstract}

Keywords: phytogeography, geobotany, soil-vegetation relationships, Brazilian semiarid region.

\section{INTRODUÇÃO}

Em razão da extensa área geográfica, a região do Médio São Francisco compreende uma grande zona de transição (ecótone) entre domínios morfoclimáticos e fitogeográficos (Ab’Sáber, 2003). Quase todo o território é associado ao clima semiárido, predominado por depressões interplanálticas no domínio da Caatinga, e uma estreita porção a oeste, submetida a um clima semiúmido no domínio do Cerrado, onde prevalecem planaltos (Velloso et al., 2002; Ab'Sáber, 2003). O Médio São Francisco representa o setor oeste da Depressão Sertaneja Meridional, que inclui outros ecossistemas como as Dunas do São Francisco (grande região de areias quartzosas) e uma pequena parte do Complexo da Chapada Diamantina, com relevo movimentado e grande heterogeneidade ambiental (Velloso et al., 2002).

Essa região está inserida no centro do Cráton do São Francisco, com grau baixo ou nulo de metamorfismo, com relevos suavizados e topografia de ampla depressão relativa (Schaefer, 2013). No passado, a região foi contemplada com múltiplos episódios de sedimentação, tanto marinha, como rochas pelíticas e calcários do Grupo Bambuí, quanto continental, arenitos da Formação Urucuia e Areado, constituindo assim um local com grande diversidade geológica e ambiental (Schaefer, 2013).

A formação geológica básica do semiárido consiste em duas províncias, uma cristalina e outra sedimentar. A província cristalina (gnaisse e granito) apresenta solos rasos, pedregosos e com água superficial e subterrânea, geralmente muito mineralizada (Matallo Jr, 2000). A província sedimentar apresenta solos profundos, com boa retenção de água e topografia plana (Matallo Jr, 2000). A primeira província possui um domínio de Luvissolos e Planossolos, que estão associados à argila de atividade alta na porção mais seca ao norte; e a segunda, um domínio de Latossolos na porção mais úmida ao sul e oeste (Schaefer, 2013).

A grande diversidade geológica e edáfica do Médio São Francisco permite essa região abrigar um complexo grupo de formações vegetais, cujas preferências ambientais são inferidas, mas ainda pouco esclarecidas. Por causa do predomínio do clima semiárido na região, os fatores edáficos são considerados bons determinantes para o estabelecimento de populações de espécies vegetais (Queiroz, 2006; Santos et al., 2012; Arruda et al., 2013). Estudos sobre a relação solo-vegetação evidenciam-se bem esclarecedores para diversas localidades brasileiras (Schaefer et al., 2009); no entanto, estudos mais detalhados sobre o assunto são escassos para o semiárido.

Visando a contribuição para o entendimento da relação solo-vegetação na região semiárida brasileira, este estudo objetivou determinar os atributos edáficos mais importantes para o estabelecimento de diferentes formações vegetacionais ocorrentes na área ecotonal do Médio Vale do São Francisco.

\section{MATERIAL E MÉTODOS}

\section{Área de estudo}

O Médio São Francisco é a unidade fisiográfica de maior extensão do rio, com limites que se 
estendem da foz do rio Jequitaí, em Pirapora, MG, até a barragem de Sobradinho, BA; com um total de $1.153 \mathrm{~km}$ de comprimento, ocupa $63 \%$ de toda a bacia (Figura 1). A região apresenta grande variação de altitude, chegando a 1.400 $\mathrm{m}$ nos relevos mais montanhosos da Chapada Diamantina, a $500 \mathrm{~m}$ no leito do Rio (ANA/GEF/ PNUMA/OEA, 2003). A precipitação pluvial alcança valores inferiores a $500 \mathrm{~mm} / \mathrm{ano}$ ao norte, ou superiores a $1.250 \mathrm{~mm}$ no oeste da bacia (Velloso et al., 2002).

\section{Método}

Utilizaram-se dados de perfis de solos obtidos em levantamentos pelo Serviço Nacional de Levantamento e Conservação de Solos, atual Centro Nacional de Pesquisa de Solos - CNPS (Embrapa, $1976 ; 1977 ; 1979)$, que abrangeram toda a extensão do Médio São Francisco. Foram coligidos e tabulados os atributos físicos e químicos dos horizontes $\mathrm{A} \mathrm{e} \mathrm{B}$ e a altitude e formação vegetal (fase de vegetação) de cada perfil. Perfis de solos sem todas as informações utilizadas foram desconsiderados como Neossolos (Quartzarênicos, Litólicos, Flúvicos), horizontes decapitados, entre outros. Após essa triagem, foram utilizados 166 perfis de solos.

Com base nas características das formações vegetais descritas pelos pedólogos nos levantamentos utilizados, essas formações foram agrupadas em categorias de vegetações, considerando a terminologia adotada em IBGE (2012). Dessa forma, as formações "caatinga hiperxerófila" e "transição caatinga-cerrado" - comumente denominadas caatinga - foram consideradas savana-estépica; "caatinga hipoxerófila" foi considerada savana-estépica florestada; "cerrado caducifólio", "cerrado subcaducifólio", "cerrado", "campo cerrado" e "transição cerrado-floresta" - comumente denominadas cerrado - foram consideradas savana; "floresta caducifólia de várzea", "floresta ciliar de carnaúba", "floresta subperenifólia" e "floresta subcaducifólia" foram consideradas floresta estacional semidecidual; e "floresta caducifólia", "transição floresta-caatinga" e "transição floresta-cerrado" foram consideradas floresta estacional decidual.

Os 166 perfis foram ordenados em uma matriz de dados, onde as colunas representavam a categoria da vegetação e os atributos edáficos de cada perfil. Essa matriz foi utilizada para a análise multivariada.

\section{Análise estatística}

Para definir que variáveis seriam mais importantes para cada categoria de vegetação, foi utilizada a análise de componentes principais (PCA) com os dados dos horizontes A e B. Essa análise é

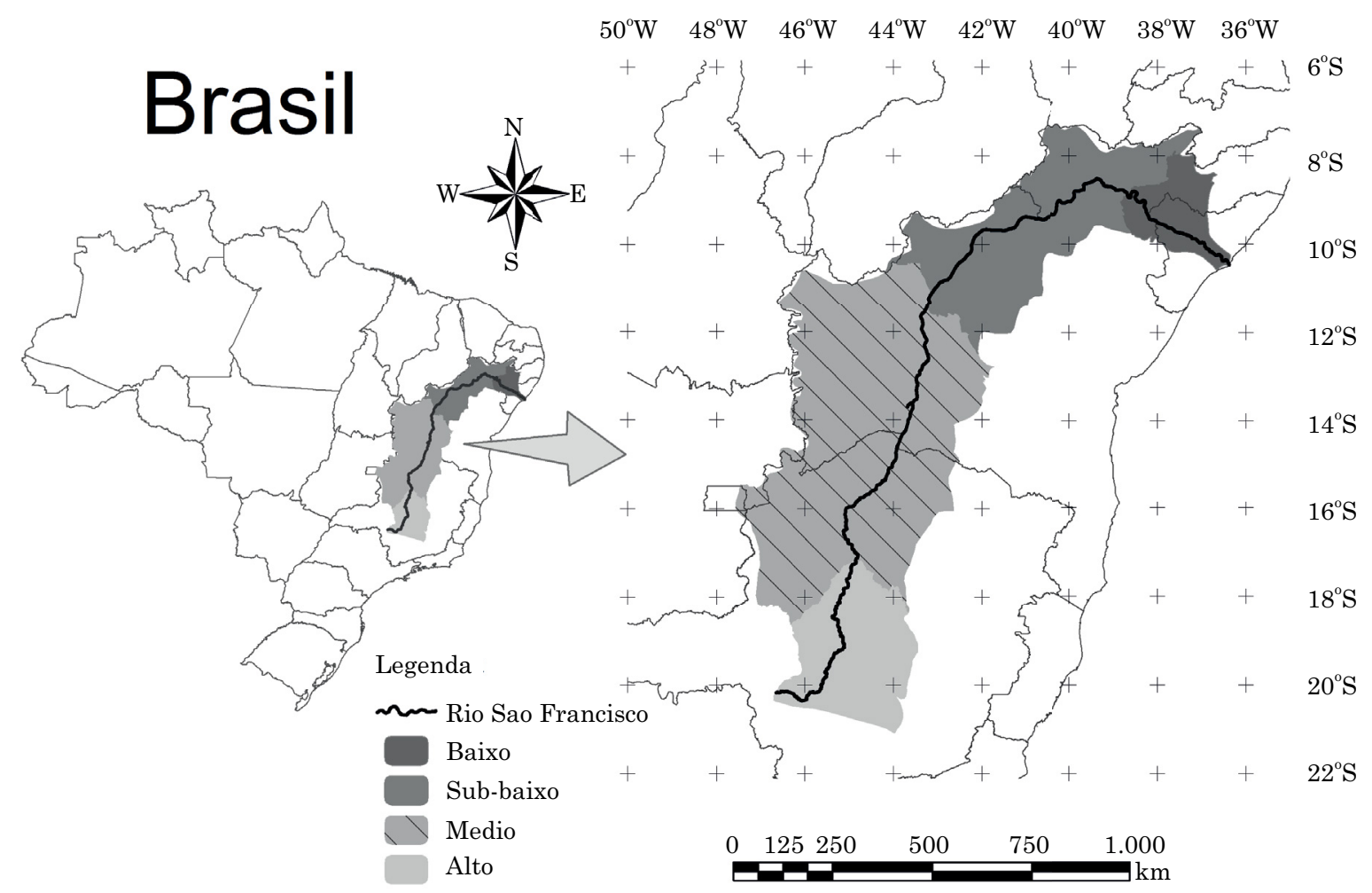

Figura 1. Bacia do rio São Francisco, Brasil, com destaque para suas sub-bacias. 
frequentemente usada para detectar colinearidade entre variáveis (Webster e Oliver, 1990; Eisenlohr, 2014) e reduzir o número de variáveis de um grande conjunto, como dados de perfis de solos (Carvalho Jr et al., 2008). Uma PCA prévia foi executada com o objetivo de indicar variáveis pouco explicativas (correlação com os dois primeiros eixos $<0,5$ ) ou com natureza colinear (Webster e Oliver, 1990). Essas variáveis foram retiradas para a confecção da PCA definitiva. Posteriormente, foi processada a análise de variância (Anova, quando paramétrico; e Kruskal-Wallis, quando não paramétrico), para verificar o efeito das variáveis isoladamente sobre as classes de vegetações. A PCA foi executada no software PC-ORD 5.0 (McCune e Mefford, 2011), com teste de randomização (999 vezes) para observar a significância dos eixos. As análises de variância foram processadas no software PAST 2.15 (Hammer et al., 2001), onde os resultados significativos foram submetidos às avaliações post-roc (teste de Tukey, quando paramétrico; e Mann-Whitney, quando não paramétrico).

\section{RESULTADOS}

Consideraram-se para a PCA as variáveis altitude, areia, argila, óxido de alumínio $\left(\mathrm{Al}_{2} \mathrm{O}_{3}\right)$, óxido de ferro $\left(\mathrm{Fe}_{2} \mathrm{O}_{3}\right)$, carbono orgânico $(\mathrm{C})$, soma de bases (SB), $\mathrm{pH}$ em KCl e saturação por bases (V), para ambos os horizontes. As variáveis silte/argila (S/A), $\mathrm{H}+\mathrm{Al}$ e altitude foram restritas à $\mathrm{PCA}$ do horizonte A, e porcentagem de sódio trocável (PST), saturação por $\mathrm{Al}(\mathrm{m})$ e profundidade do horizonte restringiram-se à PCA do horizonte $\mathrm{B}$ (Figura 2). Em ambas as PCAs, os diagramas foram apresentados com dois eixos $(p<0,01)$, com porcentagem de explicação de $66,72 \%$ para a análise dos horizontes A e $58,21 \%$ para a dos horizontes B (Quadro 1). Os resultados indicaram que a maior parte da variância foi explicada pelas variáveis analisadas, sendo o restante inferido para variáveis não analisadas e resíduos da análise.

As variáveis comuns aos dois horizontes demonstraram relações semelhantes (Figura 2), indicando que, embora seus valores se alterem entre os horizontes, suas relações com as formações vegetacionais se mantêm. Em relação à PCA do horizonte $\mathrm{A}$, as variáveis areia e argila foram fortemente correlacionadas com o eixo 1, indicando um gradiente nas propriedades físicas entre a savana-estépica e a floresta decidual. Nesse gradiente, a savana-estépica e a maioria dos perfis em savana evidenciaram-se associadas aos solos arenosos na porção negativa do eixo, enquanto a maioria dos perfis em floresta decídua associou-se a solos mais argilosos (além de maiores teores de óxidos, C e soma de bases) na porção positiva. Já em relação ao eixo 2 , os perfis de savana-estépica florestada
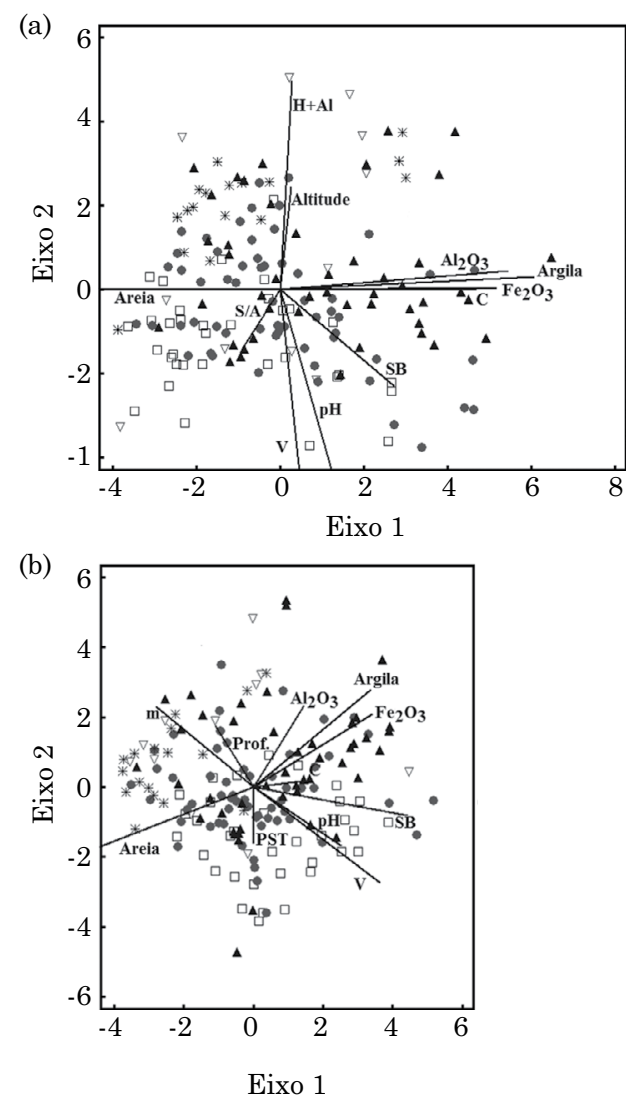

Figura 2. Diagrama da análise de componentes principais (PCA) para os horizontes A (a) e B (b) de perfis amostrados no Médio rio São Francisco, Brasil. Os símbolos correspondem às classes de vegetação, sendo savana-estépica ( $\square$ ), savana-estépica florestada (•), savana (*), floresta estacional semidecídua $(\Delta)$ e floresta estacional decídua $(\Delta)$; e as siglas dos vetores correspondem a relação silte/argila (S/A), soma de bases (SB), saturação por bases (V), saturação por alumínio $(\mathrm{m})$, porcentagem de sódio trocável (PST), profundidade do horizonte (Prof.) e porcentagem de carbono $(C)$.

e savana-estépica tiveram maior associação com saturação por maiores teores de bases e maior pH na porção negativa do eixo, enquanto savana apresentou-se mais associada a maiores altitudes e maior acidez total $(\mathrm{H}+\mathrm{Al})$, na porção positiva do eixo. Savana-estépica também apresentou maior relação silte/argila.

Em relação à PCA do horizonte $\mathrm{B}$, savana-estépica e savana-estépica florestada foram associadas a maiores valores de $\mathrm{pH}$, soma de bases, saturação por bases e baixos valores de saturação por $\mathrm{Al}$, em solos rasos. Os perfis em floresta semidecídua foram aliados aos solos com elevados teores de óxidos e argila. Já a savana foi agregada a solos mais arenosos, com baixos teores de óxidos. 
Embora importantes para a PCA, as análises de variância não evidenciaram significância, em ambos os horizontes, para as variáveis óxido de $\mathrm{Fe}$ e $\mathrm{Al}$ (Quadro 2). As variáveis que apresentaram diferença significativa entre as formações vegetais

Quadro 1. Análises de componentes principais (PCA) para os horizontes A e B e correlações com os dois primeiros eixos

\begin{tabular}{lcccc}
\hline & \multicolumn{2}{c}{ Horizonte A } & \multicolumn{2}{c}{ Horizonte B } \\
\hline Eixos & 1 & 2 & 1 & 2 \\
Autovalor & 4,79 & 3,21 & 4,02 & 2,97 \\
\% da variância & 39,91 & 26,80 & 33,49 & 24,73 \\
Valor-p & $<0,01$ & $<0,01$ & $<0,01$ & $<0,01$ \\
Areia & 0,93 & 0,05 & 0,79 & $-0,49$ \\
Argila & $-0,92$ & 0,21 & $-0,68$ & $-0,62$ \\
$\mathrm{Al}_{2} \mathrm{O}_{3}$ & $-0,87$ & 0,25 & $-0,45$ & 0,57 \\
$\mathrm{Fe}_{2} \mathrm{O}_{3}$ & $-0,85$ & 0,07 & $-0,69$ & 0,54 \\
$\mathrm{C}$ orgânico & $-0,81$ & $-0,03$ & $-0,47$ & 0,17 \\
$\mathrm{SB}$ & $-0,62$ & $-0,57$ & $-0,78$ & $-0,34$ \\
$\mathrm{pH}(\mathrm{KCl})$ & $-0,42$ & $-0,79$ & $-0,59$ & $-0,48$ \\
$\mathrm{~S} / \mathrm{A}$ & 0,36 & $-0,45$ & - & - \\
$\mathrm{V}$ & $-0,30$ & $-0,90$ & $-0,71$ & $-0,62$ \\
$\mathrm{H}+\mathrm{Al}$ & $-0,20$ & 0,83 & - & - \\
$\mathrm{Altitude}$ & $-0,19$ & 0,54 & - & - \\
$\mathrm{PST}$ & - & - & $-0,01$ & $-0,47$ \\
$\mathrm{~m}$ & - & - & 0,31 & 0,33 \\
$\mathrm{Profundidade}$ & - & - & 0,39 & 0,49 \\
\hline
\end{tabular}

Quadro 2. Análise de variância para os atributos analisados nos horizontes $\mathrm{A}$ e $\mathrm{B}$, em razão das classes de vegetação

\begin{tabular}{lcccc}
\hline \multirow{2}{*}{ Variável } & \multicolumn{2}{c}{ Horizonte A } & \multicolumn{2}{c}{ Horizonte B } \\
\cline { 2 - 5 } & $\begin{array}{c}\text { Valor do } \\
\text { teste }\end{array}$ & Valor-p & $\begin{array}{c}\text { Valor do } \\
\text { teste }\end{array}$ & Valor-p \\
\hline Areia & $\mathrm{H}=16,42$ & $\mathrm{p}<0,01$ & $\mathrm{H}=18,15$ & $\mathrm{p}<0,01$ \\
Argila & $\mathrm{H}=19,14$ & $\mathrm{p}<0,01$ & $\mathrm{H}=14,27$ & $\mathrm{p}<0,01$ \\
$\mathrm{Al}_{2} \mathrm{O}_{3}$ & $\mathrm{~F}=2,23$ & $\mathrm{p}=0,07$ & $\mathrm{~F}=2,14$ & $\mathrm{p}=0,08$ \\
$\mathrm{Fe}_{2} \mathrm{O}_{3}$ & $\mathrm{~F}=2,23$ & $\mathrm{p}=0,07$ & $\mathrm{H}=8,52$ & $\mathrm{p}=0,07$ \\
$\mathrm{C}$ orgânico & $\mathrm{F}=12,08$ & $\mathrm{p}<0,01$ & $\mathrm{H}=28,72$ & $\mathrm{p}<0,01$ \\
$\mathrm{SB}$ & $\mathrm{H}=29,64$ & $\mathrm{p}<0,01$ & $\mathrm{H}=51,71$ & $\mathrm{p}<0,01$ \\
$\mathrm{pH}(\mathrm{KCl})$ & $\mathrm{H}=21,77$ & $\mathrm{p}<0,01$ & $\mathrm{H}=19,41$ & $\mathrm{p}<0,01$ \\
$\mathrm{~S} / \mathrm{A}$ & $\mathrm{H}=28,55$ & $\mathrm{p}<0,01$ & - & - \\
V & $\mathrm{H}=36,12$ & $\mathrm{p}<0,01$ & $\mathrm{H}=45,69$ & $\mathrm{p}<0,01$ \\
$\mathrm{H}+\mathrm{Al}$ & $\mathrm{H}=31,80$ & $\mathrm{p}<0,01$ & - & - \\
Altitude & $\mathrm{H}=42,16$ & $\mathrm{p}<0,01$ & - & - \\
PST & - & - & $\mathrm{H}=40,06$ & $\mathrm{p}<0,01$ \\
m & - & - & $\mathrm{H}=40,70$ & $\mathrm{p}<0,01$ \\
Profundidade & - & - & $\mathrm{F}=8,76$ & $\mathrm{p}<0,01$ \\
\hline
\end{tabular}

são apresentadas na figura 3 , com seus resultados post-hoc (Tukey).

Em ambos os horizontes, a savana apresentou-se mais arenosa; a floresta decídua, menos arenosa; e as demais formações apresentaram teores intermediários. $\mathrm{O}$ teor de argila variou entre os horizontes; com teor mais elevado no horizonte A, as florestas decídua e semidecídua foram as mais argilosas entre as formações avaliadas. De forma contrária, savana-estépica apresentou-se menos argilosa no horizonte $\mathrm{A}$ e com teor intermediário em B. Quanto ao teor de C orgânico, embora esse seja mais pronunciado no horizonte $\mathrm{A}$, a relação entre as formações vegetais foi similar, quando comparado ao horizonte $\mathrm{B}$, com maior teor em floresta decídua e menor em savana-estépica e savana. Em relação à soma de bases, ao $\mathrm{pH}$ e à saturação por bases, valores mais elevados foram encontrados em savana-estépica, seguido por savana-estépica florestada e floresta decídua, e menores valores para a savana. A relação silte/ argila no horizonte A foi elevada em savanaestépica e baixa em savana, sendo a floresta semidecídua similar às outras formações, em razão da sua grande variância. O teor de $\mathrm{H}+\mathrm{Al}$ no horizonte A foi elevado em floresta semidecídua e baixo em savana-estépica e savana-estépica florestada. O Na trocável foi mais elevado em savana-estépica, com grande variação entre os perfis avaliados, e baixo em savana-estépica florestada e floresta decídua. A saturação por $\mathrm{Al}$ foi elevada em savana e baixa em savana-estépica florestada, floresta decídua e savana-estépica. A profundidade do horizonte $\mathrm{B}$ foi maior em floresta semidecídua e inferior em savana-estépica. Por fim, em relação à altitude, observou-se maior valor para savana e menor para savana-estépica, com valores intermediários para as demais formações.

\section{DISCUSSÃO}

A relação entre as formações vegetais e a altitude, podendo essa ser interpretada como geoformas na escala de paisagem, revela padrão similar ao descrito por Cole (1960) para diferentes locais do semiárido brasileiro. Em geral, as savanas aparecem nas superfícies elevadas; a savana-estépica florestada ou florestas decíduas, nas encostas; e savana-estépica, nas superfícies rebaixadas (Cole, 1960).

Corroborando os resultados aqui encontrados, Motta et al. (2002) descreveram os solos de savana do Brasil Central, presente nas geoformas de topos, como sendo antigos, lixiviados, ricos em $\mathrm{Al}$ e pobres em nutrientes. Essa condição edáfica restringe o estabelecimento de outras formações não adaptadas à escassez dos recursos. Nesses ambientes, somente as vegetações escleromórficas 

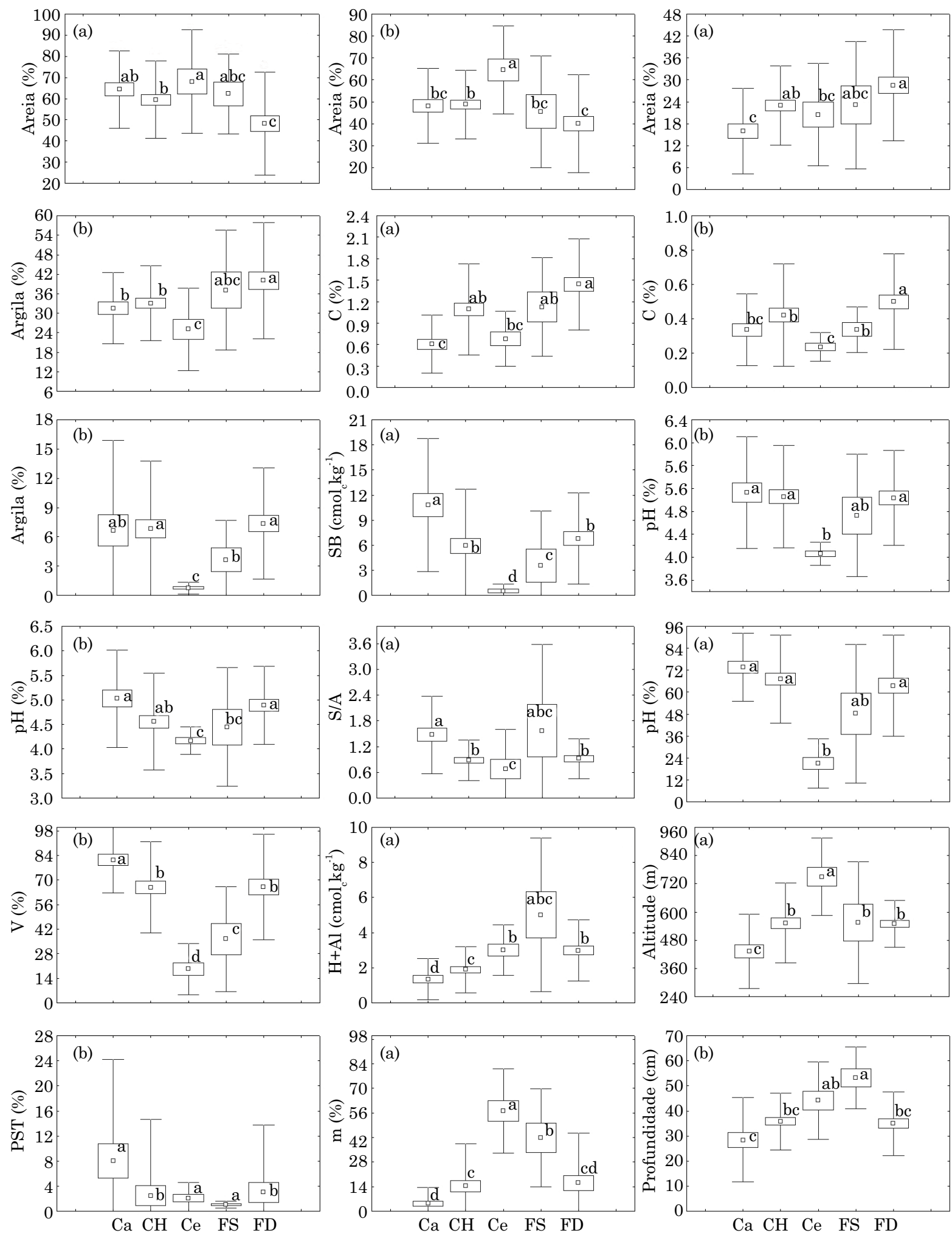

Figura 3. Box-plot das variáveis dos horizontes A e B em função das classes de vegetação (Caatinga - Ca; Caatinga Hipoxerófila - CH; Cerrado - Ce; Floresta Semidecídua - FS; Floresta Decídua - FD), onde o ponto central, o quadrado e as barras correspondem, respectivamente, à média, ao erro-padrão e ao desvio-padrão. A letra maiúscula no canto superior direito corresponde ao horizonte avaliado (exceto para altitude) e as letras minúsculas correspondem ao resultado do teste post-hoc, com p<0,05. 
conseguem tolerar a baixa disponibilidade de nutrientes, definida por xeromorfismo oligotrófico, segundo Arens (1963), potencializada pelo elevado teor de Al, definido por oligotrofismo aluminotóxico, segundo Goodland (1971).

$\mathrm{Na}$ região sul do semiárido, que faz limite com um domínio climático tropical úmido, a depressão Sertaneja Meridional é comumente ocupada por savana-estépica florestada (caatinga hipoxerófila/florestal) ou floresta decídua (IBGE, 2004; Queiroz, 2006; Santos et al., 2012; Arruda et al., 2015). De fato, parece haver mais que uma estreita relação ecológica entre essas formações. Savana-estépica florestada e floresta decídua possuem várias definições em contexto local, que por vezes são tidas como sinônimos para abordagens em maiores escalas (Prado, 2000; Pennington et al., 2000, 2006), em razão de suas similaridades florísticas e ecológicas. Além de compartilhar flora e possuir respostas fenológicas semelhantes ao clima sazonal em que se encontram, essas formações também possuem preferências edáficas semelhantes, sendo exigentes em solos de elevada fertilidade. Entre os diferentes atributos edáficos avaliados, a diferenciação entre essas formações aparece apenas nos atributos físicos, sendo a savana-estépica florestada mais arenosa e a floresta decídua mais argilosa no horizonte $\mathrm{B}$, o que também justifica maior teor de $\mathrm{C}$ orgânico e íons $\mathrm{H}^{+}$ (condizente com o atributo $\mathrm{H}+\mathrm{Al}$ ).

A maior proporção de $\mathrm{C}$ encontrada aqui para os solos de floresta decídua é resultado de sua elevada produção e decomposição da serapilheira, que é estruturalmente mais complexa, com maior biomassa que as demais formações. As folhas das espécies de floresta decídua possuem elevado teor de N, P e Ca (Jaramillo e Sanford, 1995; Rossatto et al., 2015), o que contribui ainda mais com a eutrofização superficial dos seus solos. Apesar de a savana-estépica florestada (e savana-estépica) ser decidual, sua menor biomassa não permite um input de $\mathrm{C}$ tão elevado quanto às florestas decíduas, o que resulta em menores teores de $\mathrm{C}$ orgânico superficial, como referido neste estudo. A baixa concentração de $\mathrm{C}$ no horizonte $\mathrm{A}$ dos perfis de savana-estépica, com média próxima de 0,6\% (horizonte A fraco, sensu Embrapa, 2013), também é encontrada em outros solos de caatinga do interior do semiárido (Oliveira et al., 2009).

Sendo assim, não se pode desconsiderar que a pequena diferença edáfica existente entre floresta decídua e savana-estépica florestada seja resultado de um histórico processo de antropização. Comunidades vegetais de clima semiárido submetidas à corte seletivo, ou mesmo supressão total no passado, tenderiam a apresentar menor biomassa e, consequentemente, menor acréscimo de carbono no solo. Tais ambientes tornam-se propícios a uma maior lixiviação de nutrientes pelo solo, por causa da menor cobertura do solo, se comparado a uma floresta decidual em seu estádio clímax.

As menores cotas altimétricas reveladas aqui para savana-estépica demostraram que essa formação está restrita às porções mais ao norte do Médio São Francisco, onde a bacia atinge cotas mais baixas. Diferente das baixadas da porção sul (Arruda et al., 2015), a porção norte apresenta condições bioclimáticas mais secas, com menor intensidade de processos pedogenéticos. Por essa razão, o domínio da caatinga é comumente associado a solos rasos, arenosos e pedregosos (Cole, 1960; Queiroz Neto, 1968; Ab'Sáber, 2003). Além disso, os solos da caatinga (savana-estépica) também são caracterizados por apresentarem elevada densidade e teor de $\mathrm{Na}$ (Oliveira et al., 2009), o que prejudica o crescimento e desenvolvimento das plantas. De fato, elevado teor de Na foi encontrado em savanas-estépicas deste estudo, também semelhante a Luvissolos com caráter solódico no núcleo do domínio da caatinga (Oliveira et al., 2009) e caatinga costeira da região dos Lagos no Rio de Janeiro (Ibraimo et al., 2004).

Quanto à floresta semidecídua, a grande amplitude altitudinal observada para sua ocorrência indica que essa formação está presente em diversos ambientes, podendo apresentar-se nas porções baixas associadas aos cursos d'agua, em vertentes elevadas e úmidas pela influência orográfica e em linhas de drenagens. Saturação por bases e teor de $\mathrm{Al}$ também apresentaram grande amplitude, indicando que as florestas semidecíduas não se restringem a determinadas geologias ou formas da paisagem, mas sim à disponibilidade hídrica no solo.

No que se referem aos domínios morfológicos e fitogeográficos (Ab'Sáber, 2003), o cerrado (savana) e a caatinga (savana-estépica) do Médio São Francisco não compreendem porções nucleares, e sim ecotonais. No entanto, suas características se assemelham bem aos padrões já descritos para os respectivos domínios. Essa grande área de transição entre os domínios dos cerrados e das caatingas compreende também outro domínio pouco enfatizado na literatura, o domínio das florestas decíduas (floresta estacional decídua + savana-estépica florestada), com características edáficas bem distintas dos domínios vizinhos e cuja área nuclear, com maior área contínua dessa floresta, encontra-se na zona de transição entre os domínios do cerrado e da caatinga.

\section{CONCLUSÕES}

Na região do Médio São Francisco, há ocorrência de dois espaços com características edáficas e vegetacionais bem distintas. O primeiro está 
associado aos topos arenosos e lixiviado, associados à formação de savanas; o segundo representa as superfícies mais rebaixadas, com caráter eutrófico associado às vegetações deciduais.

Grande semelhança entre savana-estépica florestada e floresta decídua foi observada, ambas dão preferências a solos eutróficos, alcalinos e profundos. Dessa forma, a diferença entre essas formações, apontada em diversos estudos, parece restringir-se ao aspecto fisionômico da vegetação. A savana-estépica apresentou solos solódicos e rasos, sempre associados a paisagens rebaixadas. Essa condição edáfica restritiva potencializa o estresse proporcionado pelo clima semiárido, limitando o estabelecimento de formações vegetais menos adaptadas.

A grande amplitude dos atributos pedológicos das florestas semidecíduas indica que essa formação ocorre em diversos tipos de ambientes, sem preferência geológica ou da forma da paisagem, desde que próximos aos cursos d'agua.

\section{AGRADECIMENTOS}

À Coordenação de Aperfeiçoamento de Pessoal de Nível Superior (CAPES), pela bolsa de doutorado de D.M.A.; e ao Conselho Nacional de Desenvolvimento Científico e Tecnológico (CNPq), pela bolsa de produtividade a C.E.G.R.S.. Ao Vitor Moura, pela ajuda na obtenção do banco de dados e aos revisores anônimos por valiosas considerações na versão final do manuscrito.

\section{REFERÊNCIAS}

Ab'sáber NA. Os domínios da natureza no Brasil: potencialidades paisagísticas. São Paulo: Ateliê; 2003.

ANA/GEF/PNUMA/OEA. Projeto de Gerenciamento Integrado das Atividades Desenvolvidas em Terra na Bacia do São Francisco, Sub-projeto 4.5.A - Diagnóstico analítico da bacia e sua zona costeira. Brasília, DF: 2003.

Arens K. As plantas lenhosas dos campos cerrados como flora adaptada às deficiências minerais do solo. In: Ferri MG, editor. Simpósio sobre o Cerrado. São Paulo: Universidade de São Paulo; 1963. p.285-303.

Arruda DM, Ferreira-JR WG, Duque-Brasil R, Schaefer CER. Phytogeographical patterns of dry forests sensu stricto in northern Minas Gerais State, Brazil. An Acad Bras Ci. 2013;85:283-94.

Arruda DM, Schaefer CER, Corrêa GR, Rodrigues PMS, R. Duque-Brasil R, Ferreira-JR WG, Oliveira-Filho AT. Landforms and soil attributes determines the vegetation structure in the Brazilian semiarid. Folia Geobot. 2015;50:175-84.
Carvalho-JR W, Schaefer CEGR, Chagas CS, Fernandes-Filho EI. Análise multivariada de Argissolos da faixa atlântica brasileira. R Bras Ci Solo. 2008;32:2081-90.

Cole MM. Cerrado, Caatinga and Pantanal: the distribution and origin of the savanna vegetation of Brazil. Geogr J. 1960;126:168-79.

Eisenlohr PV. Persisting challenges in multiple models: a note on commonly unnoticed issues regarding collinearity and spatial structure of ecological data. Braz J Bot. 2014;37:365-71.

Empresa Brasileira de Pesquisa Agropecuária - Embrapa. Levantamento exploratório-reconhecimento de solos do Norte de Minas Gerais. (Área de atuação da Sudene). Recife: 1979.

Empresa Brasileira de Pesquisa Agropecuária - Embrapa. Levantamento exploratório-reconhecimento de solos da margem esquerda do Rio São Francisco, Estado da Bahia. Recife: Embrapa-SNLS; 1976. (Boletim técnico, 38)

Empresa Brasileira de Pesquisa Agropecuária - Embrapa. Levantamento exploratório-reconhecimento de solos da margem direita do Rio São Francisco, Estado da Bahia. Recife: Embrapa-SNLS; 1977. (Boletim técnico, 52).

Empresa Brasileira de Pesquisa Agropecuária - Embrapa. Sistema brasileiro de classificação de solos. 3ª . ed. Brasília, DF: 2013.

Goodland RJA. Oligotrofismo e alumínio no cerrado. In: Ferri MG, editor. Simpósio sobre o cerrado. São Paulo: Universidade de São Paulo; 1971. p.44-50.

Hammer Ø, Harper DAT, Ryan PD. PAST: paleontologycal statistics software package for education and data analysis. Palaeont Elect. 2001;4:1-9

Ibraimo MM, Schaefer CEGR, Ker JC, Lani JL, Rolim-Neto FC, Albuquerque MA, Miranda VJ. Gênese e micromorfologia de solos sob vegetação xeromórfica (caatinga) na Região dos Lagos (RJ). R Bras Ci Solo. 2004;28:695-712.

Instituto Brasileiro de Geografia e Estatística - IBGE. Manual técnico da vegetação brasileira. Rio de Janeiro: 2012.

Instituto Brasileiro de Geografia e Estatística - IBGE. Mapa de vegetação do Brasil. Escala 1:5.000.000. 3ª ed. Brasília, DF: 2004.

Jaramillo VJ, Sanford R. Nutrient cycling in tropical deciduous forests. In: Bullock SH, Mooney HA, Medina E, editors. Seasonally dry tropical forests. Cambridge: Cambridge University Press; 1995. p.346-61.

Matallo Jr H. A desertificação no Brasil. In: Oliveira TS, Assis-Jr RN, Romero RE, Silva JRC, editores. Agricultura, sustentabilidade e o semi-árido. Fortaleza: UFC/SBCS; 2000. p.89-113.

McCune B, Mefford MJ. PC-ORD. Multivariate Analysis of Ecological Data. Version 6.0. Gleneden Beach: MjM Software Design; 2011.

Motta PEF, Carvalho-Filho A, Ker JC, Pereira NR, Carvalho-Junior W, Blancaneaux P. Relação solo-superfície geomórfica e evolução da paisagem em uma área do Planalto Central Brasileiro. Pesq Agropec Bras. 2002;37:869-78.

Oliveira LBD, Fontes MPF, Ribeiro MR, Ker JC. Morfologia e classificação de Luvissolos e Planossolos desenvolvidos de rochas metamórficas no semiárido do nordeste brasileiro. R Bras Ci Solo. 2009;33:1333-45. 
Pennington RT, Lewis GP, Ratter JA. Neotropical savannas and dry forests: plant diversity, biogeography, and conservation. Oxford: Taylor \& Francis CRC Press; 2006.

Pennington RT, Prado DE, Pendry CA. Neotropical seasonally dry forests and Quaternary vegetation changes. J Biogeogr. 2000;27:261-73.

Prado DE. Seasonally dry forests of tropical South America: from forgotten ecosystems to a new phytogeographic unit. Edinburgh J Bot. 2000;57:437-61.

Queiroz LP. The brazilian caatinga: phytogeographical pattern inferred from distribution data of the leguminosae. In: Pennington RT, Lewis GP, Ratter JA, editors. Neotropical savannas and dry forests: plant diversity, biogeography, and conservation. Oxford: Taylor \& Francis CRC; 2006. p.113-49.

Queiroz Neto JP. Os solos. In: Azevedo A, editor. Brasil: a terra e o homem, bases físicas. São Paulo: Nacional; 1968. p.463-514.

Rossatto DR, Carvalho FA, Haridasan M. Soil and leaf nutrient content of tree species support deciduous forests on limestone outcrops as a eutrophic ecosystem. Acta Bot Bras. 2015; 29:231-8.
Santos RM, Oliveira-Filho AT, Eisenlohr PV, Queiroz LP, Cardoso DBOS, Rodal MJN. Identity and relationships of the Arboreal Caatinga among other floristic units of seasonally dry tropical forests (SDTFs) of north-eastern and Central Brazil. Ecol Evol. 2012;2:409-28.

Schaefer CEGR, Mendonça BAF, Ferreira-JR WG, Valente E, Correa GR. Relações solo-vegetação em alguns ambientes brasileiros: fatores edáficos e florístico. In: Martins SV, editor. Ecologia de florestas tropicais do Brasil. Viçosa, MG: Universidade Federal de Viçosa; 2009. p.143-84.

Schaefer CEGR. Bases físicas da paisagem brasileira: estrutura geológica, relevo e solos. Tópicos Ci Solo. 2013;8:221-78.

Velloso AL, Sampaio EVSB, Pareyn FGC. Ecorregiões: propostas para o bioma Caatinga. Recife: The Nature Conservancy do Brasil; 2002.

Webster R, Oliver MA. Statistical methods in soil and land resource survey. Oxford: Oxford University Press; 1990. 